\title{
HVMANITAS
}

\section{Trasão: o único Miles da comédia terenciana}

Autor(es): $\quad$ Couto, Aires Pereira do

Publicado por: Faculdade de Letras da Universidade de Coimbra, Instituto de Estudos

URL

persistente: URI:http://hdl.handle.net/10316.2/23008

DOI: $\quad$ DOI:http://dx.doi.org/10.14195/2183-1718_63_13

Accessed : $\quad$ 26-Apr-2023 07:52:46

A navegação consulta e descarregamento dos títulos inseridos nas Bibliotecas Digitais UC Digitalis, UC Pombalina e UC Impactum, pressupõem a aceitação plena e sem reservas dos Termos e Condições de Uso destas Bibliotecas Digitais, disponíveis em https://digitalis.uc.pt/pt-pt/termos.

Conforme exposto nos referidos Termos e Condições de Uso, o descarregamento de títulos de acesso restrito requer uma licença válida de autorização devendo o utilizador aceder ao(s) documento(s) a partir de um endereço de IP da instituição detentora da supramencionada licença.

Ao utilizador é apenas permitido o descarregamento para uso pessoal, pelo que o emprego do(s) título(s) descarregado(s) para outro fim, designadamente comercial, carece de autorização do respetivo autor ou editor da obra.

Na medida em que todas as obras da UC Digitalis se encontram protegidas pelo Código do Direito de Autor e Direitos Conexos e demais legislação aplicável, toda a cópia, parcial ou total, deste documento, nos casos em que é legalmente admitida, deverá conter ou fazer-se acompanhar por este aviso. 
humanitas

Vol. LXIII

2011 


\title{
TRASÃO - O ÚNICO MILES DA COMÉDIA TERENCIANA
}

\author{
Aires Pereira do Couto \\ Universidade Católica Portuguesa
}

\section{Resumo}

No conjunto da obra terenciana, somente encontramos um exemplo de soldado fanfarrão: o miles Trasão, no Eunuchus. Esta personagem, tirada do Kolax de Menandro, foi moldada à imagem de Terêncio e contribuiu, decisivamente, para o enriquecimento do cómico da peça e para o sucesso que alcançou aquando da sua representação.

Palavras-chave: Terêncio, comédia, Eunuchus, miles, Trasão.

\begin{abstract}
Among Terence's comedies, we find one single example of a swaggering soldier: the miles Thraso, in Eunuchus. This character, taken from Menander's Kolax, was shaped in the image of Terence and contributed decisively to enrich the comicality of the play and to the success it achieved when it was performed.

Key-words: Terence, comedy, Eunuchus, miles, Thraso.

\section{Introdução}

Como se sabe, Terêncio pretendeu revolucionar a estética teatral, lutou por uma nova comédia latina, mais próxima dos modelos gregos. À comédia motoria, cheia de danças e de música, ele começou por opor uma comédia stataria, menos barulhenta, que permitisse ao público ouvir o
\end{abstract}


texto. ${ }^{1}$ Para isso pretendia acabar com os papéis de seruus currens (escravo corredor), iratus senex (velho zangado), edax parasitus (parasita comilão), sycophanta inpudens (impostor desavergonhado), e auarus leno (alcoviteiro ganancioso), como refere o dominus gregis Ambívio Turpião nos versos 35-40 do prólogo do Heautontimorumenos:

Adeste aequo animo; date potestatem mihi statariam agere ut liceat per silentium, ne semper seruos currens, iratus senex, edax parasitus, sycophanta autem inpudens, auarus leno adsidue agendi sint seni clamore summo, cum labore maxumo.

É, no entanto, indubitável que Terêncio, com o andar do tempo e à medida que foi ganhando experiência, sentiu necessidade de mais personagens cómicas que proporcionassem humor e um pouco mais de acção ruidosa; por isso foram surgindo, nas suas três últimas comédias, as primeiras personagens ditas vulgares ou algo violentas, mas saliente-se que, no entanto, ele se preocupou em retratá-las sempre com a sua habitual moderação, com o objectivo de evitar a farsa e os exageros de Plauto. ${ }^{2} \mathrm{O}$ soldado é menos ridículo, o parasita menos grosseiro, o negociante de escravos mais decente. É, de facto, o que acontece no Eunuchus (161 a.C.), com o soldado Trasão e o parasita Gnatão; no Phormio (161 a.C.), com o parasita Formião e o alcoviteiro Dorião; e, por fim, nos Adelphoe (160 a.C.), com o alcoviteiro Sanião. Esta atitude pode parecer, à primeira vista, uma tentativa de conseguir obter o favor, inicialmente negado, de um público habituado à uis comica plautina, mas, na opinião de Giovanni Cupaiuolo (1991: 90-91), o que Terêncio deseja, com a inserção destas personagens, é oferecer, num quadro que ele pretende que seja completo, a representação de todas as figuras que constituem a variedade do mundo popular da Vrbs do seu tempo.

Uma dessas personagens é, precisamente, o miles, cujas principais características são, habitualmente, a vociferação, a ostentação, a luxúria, a

${ }^{1}$ Cf. Dupont 1985: 367-368.

2 Sobre a introdução de papéis profissionais (o soldado, o parasita e o negociante de escravos) e a moderação com que Terêncio os caracteriza, vide Duckworth 1994: 267-268. 
estupidez e a cobardia. É rico, em resultado dos despojos de guerra conseguidos, e surge como um forte rival do jovem. Os exemplos mais notáveis de miles estão em Plauto, onde a personagem assume uma caricatura por vezes levada ao extremo (cf. Pirgopolinices do Miles gloriosus) ${ }^{3}$. Em toda a obra terenciana apenas encontramos um soldado fanfarrão: o miles Trasão, no Eunuchus, um soldado que, embora tão grotesco, no geral, como o soldado fanfarrão plautino, sofre algumas mudanças. Como veremos, o soldado Trasão é vaidoso, estúpido e ridículo, mas não leva estas características ao extremo e não é, apesar de tudo, tão ridículo como, por exemplo, o Pirgopolinices de Plauto, e a sua linguagem também carece do exibicionismo próprio do tipo tradicional.

\section{O soldado Trasão}

O soldado Trasão, do Eunuchus, tem, autonomamente, a sua individualidade e a sua comicidade, mas não pode, contudo, dissociar-se do parasita Gnatão ${ }^{4}$, com quem forma um duo verdadeiramente cómico, as duas personagens mais cómicas do teatro de Terêncio, na opinião de Luciano Perelli (1976: 235), com a qual concordamos. Estas duas personagens foram, de acordo com o que é dito nos versos 30-33 do prólogo do Eunuchus, importadas por Terêncio do Kolax de Menandro, peça onde aparecia um "parasita adulador" e um "soldado fanfarrão":

Colax Menandrist, in east parasitus colax

et miles gloriosus. Eas se non negat

personas transtulisse in Eunuchum suam

ex Graeca. ${ }^{5}(\ldots)$

\footnotetext{
${ }^{3}$ Acerca do miles na comédia romana, vide W. Hofmann, "Der Bramarbas bei Plautus und Terenz" in W. Hofmann and G. Wartenberg, Der Bramarbas in der antiken Komödie, Berlin, 1973, 122-130; J. A. Hanson, "The glorious military" in T. A. Dorey and D. R. Dudley (edd.), Roman drama, London, 1965, 51-67; G. E. Duckworth, the nature of Roman comedy; Bristol, 1994, 264-265; W. G. Arnott, Menander I, Cambridge, Mass. And London, 1979, xxxiii-xxxiv; S. M. Goldberg, The making of Menander's comedy, London, 1980, 45-53; T. B. L. Webster, An introduction to Menander, Manchester, 1974, 29-30; apud Barsby 1999: 157.

${ }^{4}$ Acerca do parasita Gnatão, vide Couto 2001: 261-272.

${ }^{5}$ Seguimos a edição do Eunuchus estabelecida por J. Barsby (1999).
} 
A inclusão destas duas personagens na comédia terenciana pretende, essencialmente, na nossa opinião, aumentar a comicidade da peça e divertir o público ${ }^{6}$, ainda que o soldado Trasão também contribua para a estrutura dramática, ao constituir-se, na qualidade de rival, como obstáculo à união de Fédria e de Taís. O parasita Gnatão, por sua vez, aparece como uma personagem marcada pela vivacidade da sua linguagem e destinada a fazer realçar a comicidade e a estupidez de Trasão, o soldado cuja falta de coragem contrasta com o significado do seu nome: "corajoso". Todas as suas atitudes visam levar o soldado a agir ridiculamente e a manifestar os seus estúpidos pensamentos, cabendo-lhe sublinhar, com descarados e espirituosos comentários, a parvoíce do seu parceiro ${ }^{7}$, assumindo, deste modo, a principal característica dos verdadeiros parasitas cómicos.

A primeira alusão ao soldado Trasão é feita no v. 287 pelo parasita Gnatão, quando este, saindo de casa da cortesã Taís, a quem tinha ido entregar uma jovem moça como presente do soldado, se dirige ao escravo Parmenão, que se encontrava à porta da casa de Taís, perguntando-lhe, em tom jocoso, se o deixaram ali de guarda para impedir que algum mensageiro do soldado fosse secretamente a casa da cortesã:

GN. Etiamnunc tu hic stas, Parmeno? Eho, numnam hic relictu's custos, ne quis forte internuntius clam a milite ad istam curset? (286-287)

${ }^{6}$ A eficácia do uso, por Terêncio, do parasita e do soldado é um dos principais pontos de controvérsia na avaliação do Eunuchus. Para alguns, Gnatão e Trasão são elementos intrusos, cuja principal função é a farsa, mas para outros eles contribuíram habilmente para a estrutura dramática da peça. Terêncio tem sido acusado de ter condescendido na tentação de introduzir personagens humorísticas exclusivamente com objectivos cómicos, mas há quem contra-argumente com o facto de o primeiro objectivo da comédia ser o entretenimento, e, nesse caso, estas duas personagens, verdadeiramente cómicas, fazem todo o sentido. Vide Forehand 1985: 72-73, que remete para alguns estudos sobre esta questão: G. Jachmann, "Der Eunuchus des Terenz", Nachrichten von der Gesellschaft der Wissenschaften zu Göttingen, 1921, pp.69-88; W. Ludwig, "Von Terenz zu Menander", Philologus 103 (1959) 1-38; W. Steidle, "Menander bei Terenz", Rheinisches Museum 116 (1973) 303-347; H. Lloyd-Jones, "Terentian Technique in the Adelphi and the Eunuch", Classical Quarterly 23 (1973) 279-284; G. Norwood, The Art of Terence (Oxford 1923) 64 sqq.; E. K. Rand, "The Art of Terence's Eunuchus", Transactions of the American Philological Association 63 (1932) 54-72; e K. Gilmartin, "The Thraso-Gnatho subplot in Terence's Eunuchus", Classical World 69. 4 (1975-1976) 263-267.

${ }^{7}$ Vide Posani 1962: 74. 
Embora a primeira alusão ao soldado Trasão tenha acontecido, como referimos, na cena II do acto II, a sua aparição apenas se dá no início da primeira cena do acto III (391-453), surgindo acompanhado pelo parasita Gnatão, que, à medida que vai contando ao soldado a reacção de Taís ao presente que ele lhe ofereceu, o vai lisonjeando disparatadamente, ao mesmo tempo que o tranquiliza acerca do amor de Taís, explicando-lhe como deve responder à cortesã, se ela continuar a mencionar o rival Fédria. Os primeiros 43 versos da cena (391-433) não têm uma relação directa com o enredo da peça e, presumivelmente, terão sido retirados directamente do Kolax de Menandro. Nesta primeira parte da cena, Trasão e o seu parasita Gnatão, observados pelo escravo Parmenão - que se encontra num canto da cena numa missão de reconhecimento e que, quando vê o soldado Trasão se refere a ele, em aparte, dizendo eccum militem (395), substituindo, em claro sinal de desdém, o nome próprio por militem $^{8}$-, vão nos revelando, através de um diálogo respectivamente parvo e hipócrita, o carácter de cada um deles. Mas esta primeira parte da cena não serve apenas para introduzir e caracterizar Trasão, contribui também para acrescentar comicidade à peça e salientar o carácter profundamente hipócrita e adulador de Gnatão. A segunda parte da cena, composta pelos últimos 20 versos (434-453), é mais relevante para o enredo, pois é nela que se prefigura a desavença entre a cortesã Taís e o soldado fanfarrão Trasão. ${ }^{9}$

Nesta cena, Trasão demonstra toda a credulidade tradicional do soldado, enfatizada pelos apartes do parasita Gnatão e do escravo Parmenão (418-422) e pela sua própria incapacidade de ver o quanto é ridículo (428). Acredita que tem um dom especial, que leva a que todas as pessoas the fiquem agradecidas por tudo o que faz (395-396), e vangloria-se de até o rei $^{10}$, quando andava farto dos homens e queria descansar, o levar consigo como seu único convidado; era também a ele que confiava todo o seu exército e os seus projectos (397-409). Saliente-se que a ostentação deste soldado assume uma forma diferente da habitual no soldado fanfarrão da comédia latina, pois Trasão orgulha-se não tanto dos seus sucessos militares e amorosos, mas antes da sua habilidade em agradar aos outros, da sua pretensa espirituosidade, e da inveja que a sua "superior inteligência"

\footnotetext{
${ }^{8}$ Cf. Barsby 1999: 159 n.395.

${ }^{9}$ Cf. ibid. 157.

${ }^{10} \mathrm{O}$ rei em questão não é identificado, mas trata-se, certamente, de um dos reis sucessores de Alexandre, que faleceu em 323 a. C.
} 
provocava nos seus adversários (412-426). Estamos, pois, perante um soldado que se preocupa mais com as vitórias da palavra do que com as da espada, mas a verdade é que sempre que procura ser espirituoso, não o consegue, e revela uma total incapacidade de entender o duplo sentido que a adulação de Gnatão apresenta (393-394, 397, 403, 409-410, 452-453). Esta incapacidade em perceber quando está a ser gozado resulta do facto de ele estar sempre na expectativa do elogio, expectativa bem sublinhada no verso 401, quando, prematuramente, interrompe uma fala de Gnatão, concordando desde logo com uma frase ainda incompleta. $\mathrm{O}$ seu mais intenso desejo é ser amado por Taís (446), o que contrasta, de certo modo, com a usual e absurda confidência do seu carácter irresistível.

Ao longo da maior parte da cena, Trasão é adulado pelo parasita Gnatão, que põe em prática toda a sua arte da adulação, nos moldes que ele celebrara no seu monólogo de abertura (232-269), ainda que, nos últimos versos da cena (a partir do 435), assuma outro papel: o de conselheiro do seu protector nas questões do amor, afastando-se, deste modo, da classe de parasitas aduladores e inserindo-se noutra - a dos parasitas conselheiros. É nesta qualidade que orienta Trasão no modo como se deve comportar para conseguir que a cortesã Taís fique cada vez mais apaixonada por ele (435-450).

A segunda cena em que aparece o soldado Trasão, de novo na companhia do parasita, é a cena II do acto III (454-506), precisamente no momento em que chegou a hora de Taís começar a pôr em prática o plano que já revelara ao jovem Fédria e ao escravo Parmenão: levar o soldado a pensar que ela está apaixonada por ele e, desse modo, poder ficar com a moça que ele lhe oferecera e que ela queria devolver à família. Para isso nada melhor do que receber o soldado com um salue, mi Thraso ("Olá, meu querido Trasão!") (455), um mi com vocativo que pretende sugerir ternura ou intimidade, atitude que lhe valeu de imediato um convite para jantar fora, continuando o soldado a mostrar o seu intenso desejo de ser amado por Taís (455-456), bem patente na expressão amorosa com que lhe responde ao juntar ao Thais mea (455) a interjeição $o$ e fazendo acompanhar este vocativo de uma efusiva expressão de carinho - meum sauium ("meu amor") (456) -, expressão que não volta a ser utilizada na obra terenciana. ${ }^{11}$ Pouco depois aparece Parmenão, que, ao ver Taís e Trasão, aproveita para trocar alguns mimos com o soldado e entregar à cortesã o "eunuco" e a

${ }^{11}$ Cf. Barsby 1999: 171 nn.455-456. 
etíope que ela, de imediato, leva para casa. Logo de seguida volta a sair para jantar com Trasão, que, nesta cena, pouco mais faz do que ir revelando a sua impaciência e até a sua irritação pela demora de Taís, sobretudo quando esta mantém uma conversa em voz baixa com o escravo Parmenão $(465,492,494,506)$. O soldado deixa também transparecer o seu desagrado pela apresentação dos presentes de Fédria (485-486) e a sua inabilidade para contestar a defesa que o escravo Parmenão faz da causa de Fédria (496). Em duas falas desta cena, Trasão revela ainda indícios de características próprias do tradicional soldado fanfarrão, nomeadamente no comentário lascivo que faz acerca do eunuco (479), ou quando continua a deixar transparecer a sua inabilidade para perceber que está a ser gozado (497). Como vimos, o seu papel nesta cena não é propriamente muito importante e, consequentemente, pouco contribui para a sua caracterização. O mesmo acontece em relação ao seu parceiro, o parasita Gnatão, cujas falas também são, ao contrário do sucedido na cena anterior, quase todas muito breves e circunstanciais e, além disso, em número reduzido (apenas seis). Limita-se, praticamente, a dar apoio aos insultos de Trasão (472, 487-488) e a, hipocritamente, adulá-lo mais uma vez (497-498).

O jantar de Taís e do soldado, que decorreu em casa deste, não terá corrido nada bem, de tal modo que, na cena VI do acto IV, Taís informa Cremes, o irmão da moça que o soldado lhe tinha oferecido, que o miles a quer reaver pela força e que, por isso, vai ser necessário lutar contra ele. Depois de muita insistência, Taís consegue convencer o intimidado e hesitante Cremes a fazer frente ao soldado, que voltamos a encontrar, uma vez mais, na companhia de Gnatão, numa cena particularmente cómica, a VII do acto IV (771-816), precisamente a organizar estrategicamente à volta da casa de Taís o seu "exército" - composto por três escravos e pelo seu cozinheiro, "armado" de uma esponja para limpar as feridas - com o intuito de a tomar de assalto. Com este número de "efectivos" em acção, a preocupação com a disposição estratégica dos "soldados", que parodia uma batalha, pretende, obviamente, provocar o riso. Aliás, estamos, sem dúvida, perante uma cena que apenas procura contribuir para o cómico verbal e visual da peça, já que a tentativa de tomar de assalto a casa de Taís revelar-se-á um fracasso e não terá nenhum seguimento, embora a sua integração na acção tenha sido muito bem conseguida e tenha, efectivamente, trazido muita comicidade à peça. A cena pode dividir-se, como sugere Bianco (1962: 158), em duas partes: 771-787 e 788-816. Na primeira, meramente episódica, e dedicada ao soldado e ao parasita, Trasão 
prepara os seus homens para a batalha, enquanto Gnatão salienta, louva e aprova tudo o que o miles faz. A caracterização das personagens é muito bem conseguida e produz uma notável tensão cómica. A segunda parte começa quando o soldado Trasão vê Taís, mas esta parte, ao invés da primeira, tem uma ligação directa com o enredo da peça: o miles pretende a restituição da moça que havia oferecido a Taís, mas esta recusa-se a devolvê-la e Cremes comunica ao soldado que Pânfila, assim se chama a moça, é sua irmã e uma cidadã livre.

É ao longo desta cena que melhor se define a caracterização de Trasão, que aparece com a esperada combinação de arrogância e cobardia, pois embora diga que prefere morrer a suportar uma afronta tão grande e que vai arrebatar a moça e dar uma surra a Taís (771-774), tem o cuidado de se posicionar com segurança na retaguarda, donde dará o sinal de ataque (781), ataque que vai, contudo, adiando, preferindo a negociação à força (789), e acabando mesmo por retirar o seu exército sem nada ter conseguido (814). O episódio da recuperação de Pânfila, por parte de Trasão e do seu "exército", foi tratado como uma verdadeira operação militar, pelo que são recorrentes os termos próprios da linguagem bélica ${ }^{12}$ (773: expugnabo; 774: agmen; 775 : cornum; 776: centurio... manipulus; 777: pugnare; 778: imperatoris uirtutem ... uim militum; 779: sanguine... uolnera; 781:instrue ... principia ... signum dabo; 782: instruxit; 786: fundam; 787: ex occulto caederes... fugam; 788: irruimus). A participação do parasita nesta cena imprime-lhe, através das suas elegantes graças de irónico sentido duplo, um maior brilho cómico e continua a contribuir, de sobremaneira, para enfatizar o carácter rídiculo do soldado. De facto, Gnatão continua a adular Trasão com exclamações de apoio (773: recte; probe; 774: pulchre), comentando ele próprio a sua adulação com sarcasmo e apartes irónicos acerca da cobardia de Trasão (782, 786-787, 790-791); toma o partido do soldado, começando por avisar Cremes, num tom de irónica delicadeza, do perigo que corre ao fazer de um homem tão importante um inimigo $(799,802)$, para logo de seguida responder a uma ameaça de Cremes, mas agora num tom particularmente agressivo e insultuoso, bem patente no vocativo canis (803), um exemplo único nas comédias de Terêncio ${ }^{13}$. Mas depois da argumentação de Cremes, que vai

${ }^{12}$ Cf. Barsby 1999: 230 n.771.

${ }^{13}$ Note-se que também Plauto usa a palavra canis 5 vezes no sentido injurioso, mas nunca num vocativo directo, apesar de usar nomes de animais com sentido insultuoso muito mais frequentemente do que Terêncio (cf. Barsby 1999: 237 n.803). Sobre este assunto vide Lilja 1965: 30-35. 
gradualmente revelando que a moça é de condição livre, cidadã de Atenas e sua irmã (805-806), revelação que, à medida que se vai concretizando, vai sendo acompanhada por sucessivas exclamações, mais irónicas do que de genuíno espanto, do soldado (805: hem; hui; 806: os durum), e tendo em conta que Cremes não se deixou intimidar por toda esta encenação bélica, Gnatão resolve mudar de estratégia e sugerir ao soldado um plano que nunca falha: meter o rabo entre as pernas e ordenar a retirada (811-812), "sábio conselho" que o nosso "sábio estratega" de imediato pôs em prática.

Quem, nesta cena, também contribui para a caracterização do soldado é Taís, que se refere a Trasão como sendo "um grande fanfarrão" (785: nebulo magnus est), e, rejeitando com desdém as alegações de Trasão sobre Cremes $(793,796)$, revela um total desprezo pelo soldado quando, em aparte, pergunta em jeito de desabafo: "o que é que se há-de fazer com um tipo destes?" (795), e quando, imediatamente antes de sair de cena, o ignora completamente ao dizer-lhe que arranje quem lhe responda à questão que ele lhe colocou (810). O desfecho do assalto, que, em perfeita coerência com a figura de Trasão, não deu em nada, apesar de todo o aparato que envolveu a sua preparação, contribuiu, contudo, de forma significativa para o cómico da cena.

As duas personagens provenientes do Kolax de Menandro reaparecem em cena na parte final do Eunuchus, nas últimas três cenas (1025-1094).

A brevíssima cena VII (1025-1030) é uma simples cena de transição, na qual Trasão diz a Gnatão que está decidido a entregar-se a Taís e fazer tudo o que ela mandar (1026), procurando justificar a sua atitude com uma alusão a Hércules que, cativado pela beleza da rainha da Lídia Ônfale, também ele não se importou de se submeter às suas ordens. No diálogo que mantém com o soldado, Gnatão faz uso, uma vez mais, da sua habitual adulação, elogiando o exemplo dado por Trasão (1027), para logo de seguida desejar, através de mais um dos seus típicos apartes sarcásticos, vê-lo ser agredido por ela com a sandália (1028). Este diálogo foi, certamente, presenciado pelo escravo Parmenão, ainda que não tenha tido qualquer interferência directa na cena, pois participou na anterior e reaparece na seguinte, sem que tenha havido qualquer referência a uma eventual partida e ao seu regresso.

Embora o soldado e o parasita participem na penúltima cena (10311049), juntamente com o jovem Quérea e o escravo Parmenão, os papéis invertem-se em relação à cena anterior, já que a cena é, na sua quase totalidade, preenchida por um diálogo entre Quérea e Parmenão em que 
aquele, felicíssimo, revela que se descobriu que Pânfila era cidadã, que Fédria e Taís vão ficar juntos, e que o soldado vai ser posto no olho da rua (1036-1041). O parasita e o soldado limitam-se a ouvir o referido diálogo, e Trasão, sentindo a sua vida andar para trás, apenas faz uma pergunta em que revela estar consciente de "estar perdido para sempre" (1043).

Mais significativa é a participação do soldado na última cena da peça ${ }^{14}$ (1049-1094), que nos revela um soldado mais patético do que propriamente cómico, em consequência da sua paixão exacerbada por Taís. Nesta cena fica bem patente a verdadeira adoração que Trasão tem pela cortesã, pretendendo, por isso, a qualquer custo, ficar ligado a ela. Para tal suplica, desesperado, ao parasita Gnatão que faça tudo o que estiver ao seu alcance, por meio de preces ou de dinheiro, para persuadir os jovens Fédria e Quérea a aceitarem um compromisso com ele, de modo a que possa ficar ligado, de alguma forma, a Taís (1054-1055). Gnatão põe mãos à obra para tentar levar a bom porto a sua missão, não sem antes ter conseguido do soldado a garantia de, em caso de sucesso, ter direito ao prémio mais almejado por qualquer verdadeiro parasita: que a casa do soldado esteja sempre aberta para ele e que, sem ter de ser convidado, tenha lá sempre um lugar (10581060). Mas vejamos, então, as palavras com que Gnatão (1067-1088) construiu a sua argumentação para procurar convencer Fédria e Quérea:

GN. Prius audite paucis; quod quom dixero, si placuerit, facitote.

$\mathrm{CH}$. audiamus.

GN. Tu concede paullum istuc, Thraso.

Principio ego uos ambos credere hoc mihi uehementer uelim, me huius quidquid facio id facere maxume causa mea; uerum si idem uobis prodest, uos non facere inscitiast.

PH. Quid id est?

${ }^{14}$ Esta cena tem suscitado discussões acerca da questão da conduta moral e da fraqueza humana destas personagens (Vide Forehand 1985: 74-80; P. G. Brown, "The Bodmer codex of Menander and the endings of Terence's Eunuchus and other comedies" in E. Handley and A. Hurst (edd.), Relire Ménandre (Geneve 1990) 49-61; S. M. Goldberg, Understanding Terence (Princeton 1986) 113122; D. Konstan, "Love in Terence's Eunuch: the origins of erotic subjectivity", American Journal of philology 107 (1986) 377-378 e 384-385; F. H. Sandbach, The comic theatre of Greece and Rome (London 1977) 144-145; Pepe (19711972): 141-145). 
GN. Militem riualem ego recipiundum censeo.

PH. Hem! recipiundum?

GN. Cogita modo: tu hercle cum illa, Phaedria, ut lubenter uiuis (etenim bene libenter uictitas), quod des paullumst et necessest multum accipere Thaidem; ut tuo amori suppeditari possit sine sumptu tuo ad omnia haec, magis opportunus nec magis ex usu tuo nemost: principio et habet quod det et dat nemo largius. Fatuos est, insulsus, tardus, stertit noctes et dies. Neque istum metuas ne amet mulier; facile pellas ubi uelis.

PH. Quid agimus?

GN. Praeterea hoc etiam, quod ego uel primum puto, accipit homo nemo melius prorsus neque prolixius.

$\mathrm{CH}$. Mirum ni illoc homine quoquo pacto opust.

PH. Idem ego arbitror.

GN. Recte facitis. Vnum etiam hoc uos oro, ut me in uostrum gregem Recipiatis; satis diu hoc iam saxum uorso.

PH. Recipimus.

CH. Ac lubenter.

GN. At ego pro istoc, Phaedria et tu Chaerea, hunc comedendum uobis propino et deridendum.

CH. Placet.

PH. Dignus est.

GNATÃO - Primeiro ouçam algumas palavras; quando eu tiver falado, se vos agradar, apliquem-no.

QUÉREA - Ouçamos.

GNATÃO - Tu, retira-te um pouco para aí, Trasão. (Dirigindo-se aos dois irmãos) Primeiro eu queria vivamente que vocês os dois acreditassem em mim no seguinte: tudo aquilo que eu estou a fazer, faço-o sobretudo no meu interesse; mas se isto também vos for útil, seria estupidez da vossa parte não o fazerem.

FÉDRIA - De que estás a falar?

GNATÃO - A minha opinião é que o soldado deve ser acolhido como rival. FÉDRIA - O quê?! Acolhido?

GNATÃO - Pensa um pouco. Tu, cum raio, Fédria, embora vivas alegre com ela (e é um facto que levas uma vida bem alegre), tens pouco para lhe dar, e 
Taís necessita de receber muito. Para poder ajudar ao teu amor sem despesas para ti, para tudo isto, não há ninguém mais indicado nem mais útil; primeiro, ele não só tem muito que dar, mas também não há ninguém que seja mais mãos-largas. É idiota, imbecil, molengão, ronca dia e noite. E não receies que uma mulher se apaixone por ele; expulsa-lo facilmente quando quiseres.

FÉDRIA - Que fazemos?

GNATÃO - Além disso, há outra coisa que eu considero mais importante, nenhum homem recebe melhor nem mais generosamente.

QUÉREA - É provável que um homem destes nos seja útil de uma ou de outra maneira.

FÉDRIA - Eu também acho que sim.

GNATÃO - Têm razão. Vou pedir-vos mais uma coisa: que me acolham na vossa confraria; já há bastante tempo que faço rolar esta pedra.

FÉDRIA - Acolhemos.

QUÉREA - E com gosto.

GNATÃO - E eu, em troca, Fédria e Quérea, ofereço-vos este tipo para o esfolarem e para se rirem dele.

QUÉREA - Boa ideia!

FÉDRIA - Merece-o.

Foi com este "simpático" retrato do soldado Trasão e esta "brilhante" argumentação ${ }^{15}$ - que achámos por bem traduzir - que o parasita conseguiu convencer os jovens a aceitarem o soldado como "rival" e, consequentemente, ganhar o direito ao convite vitalício para jantar à mesa do soldado Trasão, aqui retratado como um verdadeiro idiota.

A peça termina com um breve diálogo entre Gnatão e Trasão (10891093), no qual se acentua o cinismo do parasita, bem patente na descarada e cínica adulação com que este se dirige a Trasão, dizendo-lhe, ambiguamente, que lhe bastou revelar a Quérea e a Fédria o seu carácter e elogiado os seus feitos e méritos para que eles concordassem em que ficasse ligado a Taís (1089-1091):

GN. Quid? Isti te ignorabant. Postquam eis mores ostendi tuos et collaudaui secundum facta et uirtutes tuas, Impetraui.

${ }^{15}$ Sobre a forma como se encontra articulado este argumento, vide Couto 2001: 271. 
Esta fala do parasita mereceu um "notável" comentário final de Trasão, uma vez mais bem revelador do seu carácter (1091-1092), no qual, embora agradeça ao parasita Gnatão a sua intervenção, tem a desfaçatez de afirmar que nunca esteve onde quer que fosse sem que todos gostassem muito dele:

TH. Bene fecisti; gratiam habeo maxumam.

Numquam etiam fui usquam quin me omnes amarent plurumum.

Este comentário, estúpido e verdadeiramente pretensioso, com que Trasão felicitou a notícia da sua aceitação como "rival" de Fédria, levou Gnatão a dirigir-se aos dois jovens com um comentário final pleno de ironia: "Eu não vos disse que havia nele uma esperteza ática?"16 (1093):

Dixin ego in hoc esse uobis Atticam elegantiam?

Assim termina a história do Eunисo, sem dúvida a mais feliz e afortunada comédia de Terêncio, que, ao ser representada duas vezes no mesmo dia e rendendo ao poeta oito mil sestércios, valor até então nunca alcançado, se tornou, de facto, num verdadeiro "êxito comercial". Para o sucesso da peça contribuiu o feliz resultado da contaminatio de duas peças de Menandro: o Eunuchus, que forneceu a intriga principal, e o Kolax, que inspirou as personagens do parasita e do soldado, personagens que, na nossa opinião, enriqueceram, indubitavelmente, a peça sob o ponto de vista da comicidade. ${ }^{17}$

Em jeito de conclusão, diga-se que Terêncio não se limitou a reproduzir o miles Trasão do Kolax de Menandro, ${ }^{18}$ retocou-o com as cores próprias da sua habitual moderação e sensibilidade, transformando-o num dos ingredientes com que conseguiu tratar, de uma forma subtil - como é sua característica - mas também verdadeiramente divertida, o tema da fraqueza

${ }^{16}$ Os atenienses eram célebres pela sua sofisticação, descrita pelos romanos através de termos como sal (Cícero, Fam.9.15.2) e lepor (Marcial 3.20.9); apud Barsby 1999: 289 n.1093.

${ }^{17}$ Esta opinião não é de todo pacífica, pois tem levantado alguma controvérsia a importância destas duas personagens na peça. (Sobre este assunto vide Forehand 1985: 72-74).

${ }^{18}$ Cf. Barsby 1999: 158. 
humana, facto que contribuiu, sem dúvida, para o sucesso que a peça alcançou aquando da sua representação.

\section{Bibliografia}

Barsby, J. (1999), Terence - Eunuchus, Cambridge University Press.

Bianco, O. (1962), Terenzio - Problemi e aspetti dell' originalità, Roma, Edizioni dell' Ateneo.

Couto, A. P. (2001), "O parasita na obra de Terêncio - Gnatão vs. Formião" in M. F. Brasete (coord.), Máscaras, Vozes e Gestos: nos caminhos do Teatro Clássico, Aveiro, Universidade, 259-284. (2008), Terêncio - Comédias I, Lisboa, INCM, 331-457 (introdução, versão do latim e notas do Еиписо).

Cupaiuolo, G. (1991), Terenzio teatro e società, Napoli, Loffredo Editore. Duckworth, G. E. (1994), The nature of Roman comedy. A study in popular entertainment. Second Edition with a foreword and bibliographical appendix by Richard Hunter, Oklahoma.

Dupont, F. (1985), L'acteur-roi ou le théâtre dans la Rome antique, Paris, Les Belles Lettres.

Forehand, W. E. (1985), Terence, Boston, Twayne Publishers.

LiLJA, S. (1965), Terms of abuse in Roman Comedy, Helsinki, Suomalainen Tiedeakatemia.

PePe, G. M. (1971-1972), “The last scene of Terence's Eunuchus”, Classical World 65: 141-145.

Perelli, L. (1976), Il teatro rivoluzionario di Terenzio, Firenze, la Nuova Itália.

Posani, M. R. (1962), “Aspetti del comico in Terenzio", Atene e Roma 7: 65-76. 